\title{
Case Report \\ Survival after Cardiac Arrest Secondary to Massive Pulmonary Embolism
}

\author{
Abdullah E. Laher (D), ${ }^{1,2}$ Muhammed Moolla, ${ }^{1,2}$ Feroza Motara, ${ }^{1}$ \\ Fathima Paruk, ${ }^{2}$ and Guy Richards ${ }^{2}$ \\ ${ }^{1}$ Department of Emergency Medicine, Faculty of Health Sciences, University of the Witwatersrand, 7 Jubilee Road, \\ Parktown, Johannesburg 2193, South Africa \\ ${ }^{2}$ Department of Critical Care, Faculty of Health Sciences, University of the Witwatersrand, 7 Jubilee Road, Parktown, \\ Johannesburg 2193, South Africa
}

Correspondence should be addressed to Abdullah E. Laher; abdullahlaher@msn.com

Received 2 August 2017; Revised 13 December 2017; Accepted 4 January 2018; Published 31 January 2018

Academic Editor: Vasileios Papadopoulos

Copyright (C) 2018 Abdullah E. Laher et al. This is an open access article distributed under the Creative Commons Attribution License, which permits unrestricted use, distribution, and reproduction in any medium, provided the original work is properly cited.

Introduction. It is estimated that the diagnosis of pulmonary embolism (PE) is missed in as many as $84 \%$ of all cases of PE. Cardiac arrest following PE is generally associated with poor outcomes. Case Report. A 43-year-old man presented to the Emergency Department (ED) in cardiac arrest. Swelling of his right lower limb was noted on arrival. Point of care ultrasound was performed during ongoing cardiopulmonary resuscitation (CPR) and showed a thrombus in the right iliofemoral vein as well as dilatation of the right ventricle. Fibrinolytic therapy was initiated immediately and a return of spontaneous circulation (ROSC) was achieved 30 minutes later. The diagnosis of $\mathrm{PE}$ was finally confirmed on computed tomography pulmonary angiography once haemodynamic stability was achieved. The patient was thereafter transferred to the intensive care unit for postresuscitation care and further management. Several days later, he was discharged home neurologically intact and fully recovered. Discussion. Since outcomes after cardiac arrest following PE are generally dismal, available and potentially life-saving interventions to restore pulmonary circulation should be rapidly implemented when PE is the likely cause of cardiac arrest.

\section{Introduction}

Pulmonary embolism (PE) is regarded as an elusive diagnosis with a non-specific clinical presentation and has a tendency to be both over- and underdiagnosed in clinical practice $[1,2]$. In the United States of America, venous thromboembolism (VTE) has been reported as the 3rd commonest cause of mortality [3]. Most patients with PE are clinically asymptomatic. In fact PE has been shown to be present in $60-80 \%$ of individuals with confirmed deep vein thrombosis (DVT), despite absence of symptom in more than half of these patients [4]. Cardiac arrest following PE has an associated mortality of up to $70 \%$ within the first hour of presentation [5] and an overall mortality of up to 95\% [6]. Approximately $90 \%$ of episodes of cardiac arrests occur within 1-2 hours after the onset of symptoms of PE $[7,8]$.
Barring a handful of case reports and a few small and predominantly retrospective studies, no randomized controlled trial has thus far focused on the management of presumed PE in cardiac arrest victims. In this manuscript we present a case of neurologically intact survival after successful thrombolysis during cardiac arrest secondary to PE. We also discuss current guidelines and recommendations.

\section{Case Report}

A 43-year-old man was rushed into the Emergency Department (ED) whilst undergoing cardiopulmonary resuscitation (CPR). Witnessed cardiac arrest had occurred during transportation to the hospital for sudden onset of shortness of breath. His initial cardiac rhythm on ED arrival was recorded as pulseless electrical activity (PEA). After confirming correct 


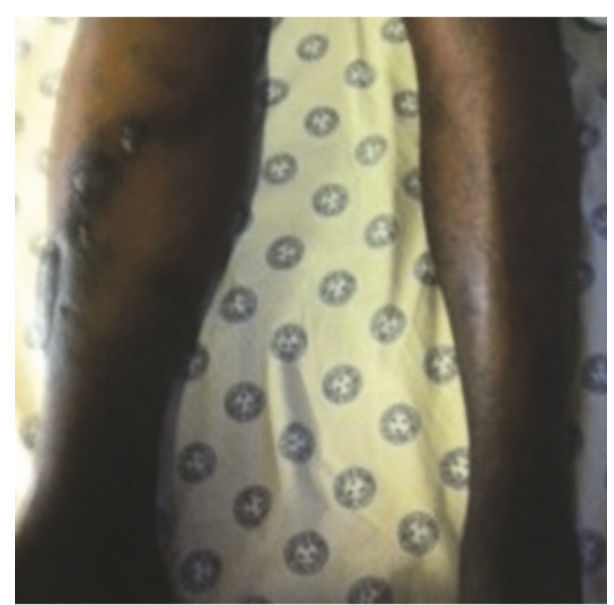

Figure 1: The right lower limb was noted to be larger than the left lower limb on arrival to the Emergency Department.

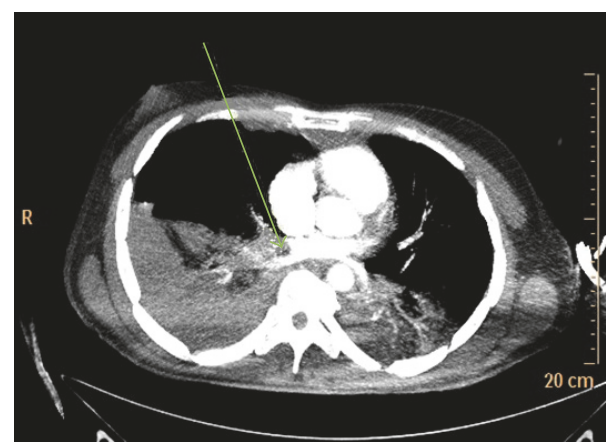

FIGURE 2: Coronal slice contrast enhanced computed tomography pulmonary angiography. The arrow demonstrates a large filling defect (pulmonary embolus) in the right pulmonary artery with an oligaemic right lung field.

endotracheal tube placement, he was noted to have significant swelling of his entire right lower limb (Figure 1). A right sided iliofemoral DVT and dilatation of the right ventricle were demonstrated on point of care ultrasound assessment that had been performed in the ED. Thrombolytic therapy with alteplase (Actilase ${ }^{\circledR}$, Boehringer Ingelheim Pharma GmbH \& Co, Germany), $100 \mathrm{mg}$ (10 mg over 1 minute and then $90 \mathrm{mg}$ over 2 hours), was promptly initiated whilst high quality $\mathrm{CPR}$ was continued. A return of spontaneous circulation (ROSC) was achieved approximately 30 minutes later. The patient remained haemodynamically stable and was sent to the radiology department for a computed tomography pulmonary angiogram (CTPA) after completion of the alteplase infusion. The diagnosis of PE was confirmed on CTPA, which demonstrated multiple large filling defects in both main pulmonary arteries as well as regions of pulmonary oligaemia. An area of hyperdensity in the posterior right lung region, suggestive of an intra-alveolar haemorrhage, was also noted on CTPA as well as on the post-thrombolysis but not the pre-thrombolysis chest X-ray films (Figures 2 and 3). Since this did not result in any haemodynamic or ventilatory instability, it was decided to manage the intra-alveolar

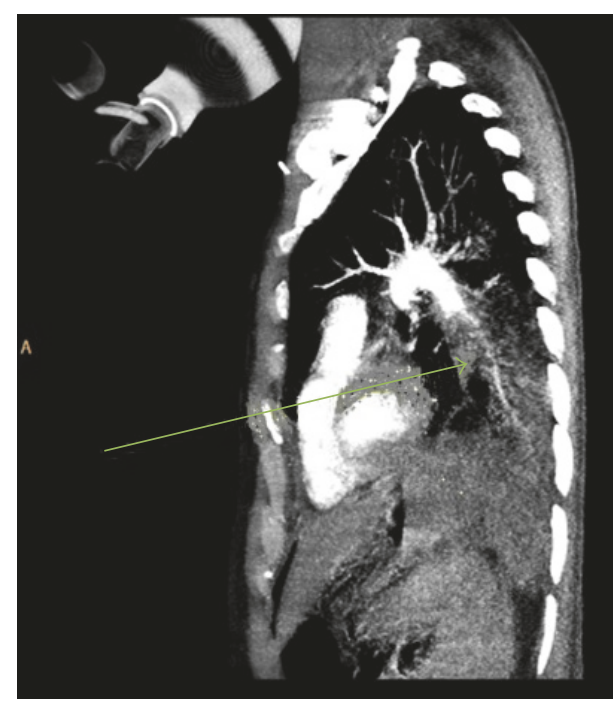

FIGURE 3: Left parasagittal contrast enhanced computed tomography pulmonary angiography. The arrow points to a large filling defect (pulmonary embolus) in the left pulmonary artery.

haemorrhage conservatively. Continuous monitoring of vital signs, including temperature, was maintained in the ICU to ensure that core body temperature remained below $37^{\circ} \mathrm{C}$. There was no need to initiate any active cooling measures. On day 3 after admission, a repeat in cardiac echocardiography demonstrated that the right ventricle had normalized in size. Further diagnostic investigations led to the conclusion that enlargement of regional inguinal lymph nodes secondary to active venereal disease precipitated the development of the lower limb DVT. Seven days after thrombolysis and treatment of his underlying pathology, the patient had completely recovered and was discharged home neurologically intact.

\section{Discussion}

High quality chest compressions, early defibrillation, and correction of the underlying cause of cardiac arrest are the only three interventions that have been shown to improve outcomes in victims of cardiac arrest. Pulmonary thromboembolism, a well-known and reversible cause of cardiac arrest, is responsible for up to $9 \%$ of all cases of cardiac arrest $[9,10]$. Other common reversible causes of cardiac arrest include hypoxaemia, potassium, and other electrolyte disturbances, hypo- or hyperthermia, acidosis, circulatory shock, tension pneumothorax, cardiac tamponade, myocardial infarction, and various toxins [11].

Pulmonary embolism as a cause of cardiac arrest is frequently missed. A post-mortem study by Kürkciyan and colleagues reported that PE as a cause of cardiac arrest was missed in $30 \%$ of all PE related cardiac arrest cases [12], whereas another autopsy study that included 16 postoperative patients documented the presence of $\mathrm{PE}$ in $62.5 \%$ of these patients [13].

External femoral vein obstruction and stasis was considered to be the cause of VTE in our patient. However, up 
to $30 \%$ of patients presenting with $\mathrm{PE}$ have no underlying risk factors [7], and many cardiac arrest victims have not complained of any preceding symptoms [14]. Although a unilateral swollen leg is highly suggestive of $\mathrm{PE}$ as a cause of cardiac arrest [15], approximately $30 \%$ of VTE's do not originate in the lower limbs. Furthermore, lower limb DVT's can also be found in individuals without any clinical features of DVT (silent DVT) [16].

Point of care ultrasonography has gained increasingly importance in the Emergency Department. It is a useful tool to screen for the presence of DVT and other indicators of PE $[17,18]$. The presence of a thrombus in the lower limbs can be accurately determined by the trained ED clinician $[19,20]$. In the cardiac arrest victim, although lacking sensitivity and specificity, echocardiographic evidence of an enlarged right ventricle with a flattened interventricular septum during routine pulse check intervals supports the diagnosis of PE [21, 22]. When available, a low end tidal $\mathrm{CO} 2$ reading, measured on quantitative waveform capnography during good quality $\mathrm{CPR}$, may also support the diagnosis of PE [23]. Once the patient has been stabilised after ROSC, the diagnosis of PE can be confirmed with CTPA before complete breakdown of the thrombus has been achieved.

With regard to the implementation of therapeutic hypothermia in the post-cardiac arrest victim, previous guidelines have suggested a targeted temperature of $32-34^{\circ} \mathrm{C}$ [24]; however Nielsen and colleagues demonstrated that there was no additional benefit in maintaining the body temperature at $36^{\circ} \mathrm{C}$ (lower end of normal range) versus $33^{\circ} \mathrm{C}$ [25].

Overall there is a lack of good data supporting the use of thrombolysis in CPR [26]. However, major societal bodies have recommended its use when PE is either known or suspected as the cause of cardiac arrest [11,27]. In the TROICA study, which is the only randomized controlled trial that compared fibrinolytic therapy to placebo in patients with outof-hospital cardiac arrest of all causes, 525 out of 1050 patients received tenecteplase. The study was prematurely terminated due to futility. There were no significant differences in 30-day survival, hospital admission, ROSC, $24 \mathrm{hr}$ survival, survival to hospital discharge, or neurologic outcome between the fibrinolysis and placebo groups. However, more cases of intracranial haemorrhage had been noted in the intervention group. Pulmonary embolism as a primary cause of cardiac arrest was only confirmed in 37/1050 patients. Since this group was underpowered, a significant 30-day survival benefit of thrombolytic treatment could not be demonstrated [28]. Contrastingly, a meta-analysis, which included patients with $\mathrm{PE}$ as a cause of cardiac arrest, concluded that fibrinolytic therapy was associated with an increase in ROSC, survival to hospital discharge, and better long term neurologic outcomes [29].

Although we infused the dose of alteplase over 2 hours as per the manufacturer's recommendation [30], others have recommended a more rapid infusion strategy (e.g., a $50 \mathrm{mg}$ bolus injection of alteplase with an option for a repeat bolus 15 minutes later or an accelerated regimen of $0,6 \mathrm{mg}$ alteplase $/ \mathrm{kg}$ over 15 minutes) [31, 32].

One of the drawbacks of thrombolytic therapy includes the risk of potential intracranial and other major bleeding episodes. In a study by Janata et al. that included 66 patients with cardiac arrest secondary to PE, major bleeding complications occurred in $25 \%$ of patients who received thrombolytic therapy. There was no difference in bleeding complications between patients who had undergone CPR of more than 10 minutes duration compared to those that required less than 10 minutes of CPR. Although not statistically significant, survival to hospital discharge was also higher in the fibrinolytic therapy group (19\% versus 7\%) [33]. Considering the overall poor prognosis associated with cardiac arrest following PE, the benefits of thrombolysis may still outweigh the risk of major bleeding.

Other therapeutic options include surgical embolectomy and percutaneous mechanical thrombectomy [11, 27]. The evidence for surgical thrombectomy and percutaneous mechanical thrombectomy during CPR is weak [11]. In a retrospective study that included 13 patients who had undergone surgical embolectomy for massive PE, only 1 out of the 4 patients $(25 \%)$ with cardiac arrest survived. There were no in-hospital deaths amongst patients without cardiac arrest [34]. In another small study by Fava and colleagues, $86 \%$ of subjects survived after percutaneous mechanical thrombectomy was performed during CPR.

In conclusion, considering that outcomes after cardiac arrest are generally dismal and that fibrinolytic therapy is a potentially life-saving intervention, the ED clinician must not hesitate to administer thrombolytics whenever PE is considered the most likely cause of cardiac arrest.

\section{Consent}

Informed consent was obtained from the patient to make use of patient data and photographs and images for publication purposes.

\section{Conflicts of Interest}

The authors hereby certify that this submission is not under publication consideration elsewhere and is free of conflicts of interest.

\section{References}

[1] N. B. Hampson, "Pulmonary embolism: difficulties in the clinical diagnosis," Seminars in Respiratory Infections, vol. 10, pp. 123-30-130, 1995.

[2] B. D. Hutchinson, P. Navin, E. M. Marom, M. T. Truong, and J. F. Bruzzi, "Overdiagnosis of pulmonary embolism by pulmonary CT angiography," American Journal of Roentgenology, vol. 205, no. 2, pp. 271-277, 2015.

[3] B. Lindblad, A. Eriksson, and D. Bergqvist, "Autopsy-verified pulmonary embolism in a surgical department: Analysis of the period from 1951 to 1988," British Journal of Surgery, vol. 78, no. 7, pp. 849-852, 1991.

[4] M. D. Silverstein, J. A. Heit, D. N. Mohr, T. M. Petterson, W. M. O'Fallon, and L. J. Melton III, “Trends in the incidence of deep vein thrombosis and pulmonary embolism: a 25-year population-based study," JAMA Internal Medicine, vol. 158, no. 6, pp. 585-593, 1998. 
[5] N. Kucher, E. Rossi, M. De Rosa, and S. Z. Goldhaber, "Massive pulmonary embolism," Circulation, vol. 113, no. 4, pp. 577-582, 2006.

[6] A. Koroneos, A. Koutsoukou, D. Zervakis et al., "Successful resuscitation with thrombolysis of a patient suffering fulminant pulmonary embolism after recent intracerebral haemorrhage," Resuscitation, vol. 72, no. 1, pp. 154-157, 2007.

[7] J. A. Heit, F. A. Spencer, and R. H. White, "The epidemiology of venous thromboembolism," Journal of Thrombosis and Thrombolysis, vol. 41, no. 1, pp. 3-14, 2016.

[8] C. Schmid, S. Zietlow, T. O. F. Wagner, J. Laas, and H. G. Borst, "Fulminant pulmonary embolism: Symptoms, diagnostics, operative technique, and results," The Annals of Thoracic Surgery, vol. 52, no. 5, pp. 1102-1107, 1991.

[9] M. Pokorna, E. Necas, R. Skripsky, J. Kratochvil, M. Andrlik, and O. Franek, "How accurately can the aetiology of cardiac arrest be established in an out-of-hospital setting? Analysis by "Concordance in Diagnosis Crosscheck Tables"," Resuscitation, vol. 82, no. 4, pp. 391-397, 2011.

[10] D. Bergum, T. Nordseth, O. C. Mjølstad, E. Skogvoll, and B. O. Haugen, "Causes of in-hospital cardiac arrest - Incidences and rate of recognition," Resuscitation, vol. 87, pp. 63-68, 2015.

[11] C. W. Callaway, J. Soar, M. Aibiki et al., "Part 4: Advanced life support: 2015 International consensus on cardiopulmonary resuscitation and emergency cardiovascular care science with treatment recommendations," Circulation, vol. 132, pp. S84S145, 2015.

[12] I. Kürkciyan, G. Meron, F. Sterz et al., "Pulmonary embolism as a cause of cardiac arrest: presentation and outcome," JAMA Internal Medicine, vol. 160, no. 10, pp. 1529-1535, 2000.

[13] O. Hauch, L. N. Jørgensen, S. C. Khattar et al., "Fatal pulmonary embolism associated with surgery. An autopsy study," Acta Chirurgica Scandinavica, vol. 156, pp. 747-749, 1990.

[14] J. A. Heit, M. D. Silverstein, D. N. Mohr, T. M. Petterson, W. M. O'Fallon, and L. J. Melton III, "Risk factors for deep vein thrombosis and pulmonary embolism: a population-based case-control study," JAMA Internal Medicine, vol. 160, no. 6, pp. 809-815, 2000.

[15] I. E. Konstantinov, P. Saxena, M. D. Koniuszko, J. Alvarez, and M. A. J. Newman, "Acute massive pulmonary embolism with cardiopulmonary resuscitation: management and results," Texas Heart Institute Journal, vol. 34, pp. 41-46, 2007.

[16] R. D. Hull, J. Hirsh, C. J. Carter et al., "Pulmonary angiography, ventilation lung scanning, and venography for clinically suspected pulmonary embolism with abnormal perfusion lung scan," Annals of Internal Medicine, vol. 98, no. 6, pp. 891-899, 1983.

[17] A. Squizzato, L. Galli, and V. E. A. Gerdes, "Point-of-care ultrasound in the diagnosis of pulmonary embolism," Critical Ultrasound Journal, vol. 7, no. 1, article no. 7, 2015.

[18] M. R. Whitson and P. H. Mayo, "Ultrasonography in the emergency department," Critical Care, vol. 20, no. 1, article no. 227, 2016.

[19] R. A. Poley, J. L. Newbigging, and M. L. A. Sivilotti, "Estimated effect of an integrated approach to suspected deep venous thrombosis using limited-compression ultrasound," Academic Emergency Medicine, vol. 21, no. 9, pp. 972-980, 2014.

[20] F. Pomero, F. Dentali, V. Borretta et al., "Accuracy of emergency physician-performed ultrasonography in the diagnosis of deep-vein thrombosis: A systematic review and meta-analysis," Thrombosis and Haemostasis, vol. 109, no. 1, pp. 137-145, 2013.
[21] P. MacCarthy, A. Worrall, G. McCarthy, and J. Davies, “The use of transthoracic echocardiography to guide thrombolytic therapy during cardiac arrest due to massive pulmonary embolism," Emergency Medicine Journal, vol. 19, no. 2, pp. 178-179, 2002.

[22] C. Bova, F. Greco, G. Misuraca et al., "Diagnostic utility of echocardiography in patients with suspected pulmonary embolism," The American Journal of Emergency Medicine, vol. 21, no. 3, pp. 180-183, 2003.

[23] B. E. Heradstveit, K. Sunde, G.-A. Sunde, T. Wentzel-Larsen, and J.-K. Heltne, "Factors complicating interpretation of capnography during advanced life support in cardiac arrest-a clinical retrospective study in 575 patients," Resuscitation, vol. 83, no. 7, pp. 813-818, 2012.

[24] J. P. Nolan, P. T. Morley, T. L. V. Hoek, and R. W. Hickey, "Therapeutic hypothermia after cardiac arrest: An advisory statement by the Advanced Life Support Task Force of the International Liaison Committee on Resuscitation," Circulation, vol. 108, no. 1, pp. 118-121, 2003.

[25] N. Nielsen, J. Wetterslev, T. Cronberg et al., "Targeted temperature management at $33^{\circ} \mathrm{C}$ versus $36^{\circ} \mathrm{C}$ after cardiac arrest," The New England Journal of Medicine, vol. 369, pp. 2197-2206, 2013.

[26] K. Namiranian, N. K. Rathi, J. Banchs, K. J. Price, J. L. Nates, and S. A. Haque, "Does thrombolysis have a place in the cardiopulmonary resuscitation of patients with acute pulmonary embolism? A case of successful thrombolysis during pulmonary embolism induced cardiopulmonary arrest," Critical Care Medicine, vol. 44, no. 5, pp. e300-e303, 2015.

[27] A. Truhlář, C. D. Deakin, J. Soar et al., "European resuscitation council guidelines for resuscitation 2015: section 4. cardiac arrest in special circumstances," Resuscitation, vol. 95, pp. 148201, 2015

[28] B. W. Böttiger, H.-R. Arntz, D. A. Chamberlain et al., "Thrombolysis during resuscitation for out-of-hospital cardiac arrest," The New England Journal of Medicine, vol. 359, no. 25, pp. 26512662, 2008.

[29] X. Li, Q.-L. Fu, X.-L. Jing et al., "A meta-analysis of cardiopulmonary resuscitation with and without the administration of thrombolytic agents," Resuscitation, vol. 70, no. 1, pp. 31-36, 2006.

[30] "Actilyse ${ }^{\circledR}$ powder and solvent for solution for injection and infusion $10 \mathrm{mg}, 20 \mathrm{mg}$ and $50 \mathrm{mg}$," 2017.

[31] S. V. Konstantinides and S. Wärntges, "Acute phase treatment of venous thromboembolism: Advanced therapy systemic fibrinolysis and pharmacomechanical therapy," Thrombosis and Haemostasis, vol. 113, no. 6, pp. 1202-1209, 2015.

[32] B. T. Fengler and W. J. Brady, "Fibrinolytic therapy in pulmonary embolism: an evidence-based treatment algorithm," The American Journal of Emergency Medicine, vol. 27, no. 1, pp. 84-95, 2009.

[33] K. Janata, M. Holzer, I. Kürkciyan et al., "Major bleeding complications in cardiopulmonary resuscitation: the place of thrombolytic therapy in cardiac arrest due to massive pulmonary embolism," Resuscitation, vol. 57, no. 1, pp. 49-55, 2003.

[34] S. Yavuz, F. Toktas, T. Goncu et al., "Surgical embolectomy for acute massive pulmonary embolism," International Journal of Clinical and Experimental Medicine, vol. 7, pp. 5362-5375, 2014. 


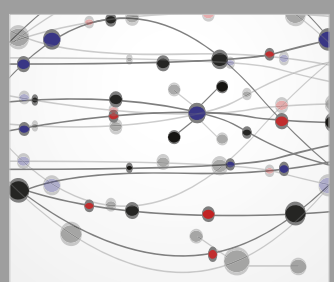

The Scientific World Journal
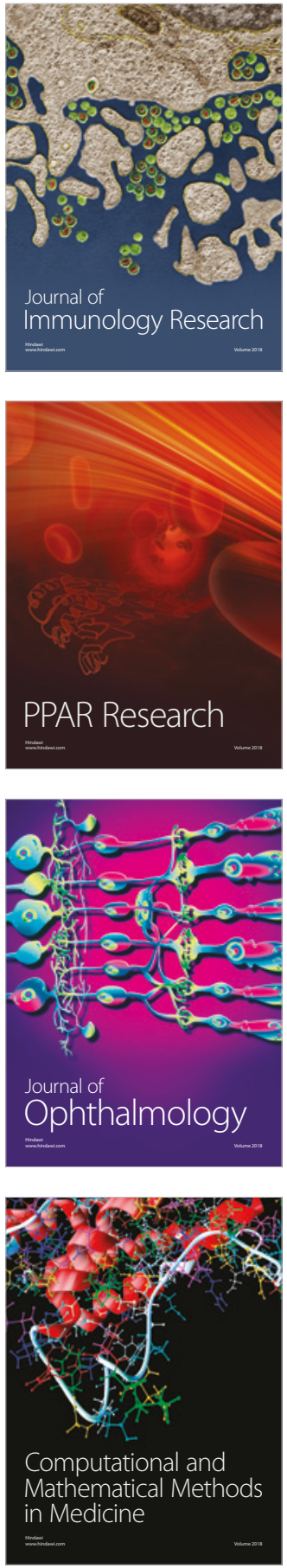

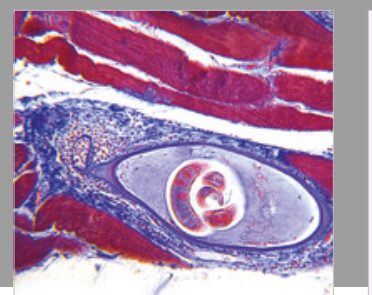

Gastroenterology Research and Practice

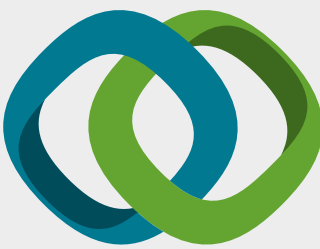

\section{Hindawi}

Submit your manuscripts at

www.hindawi.com
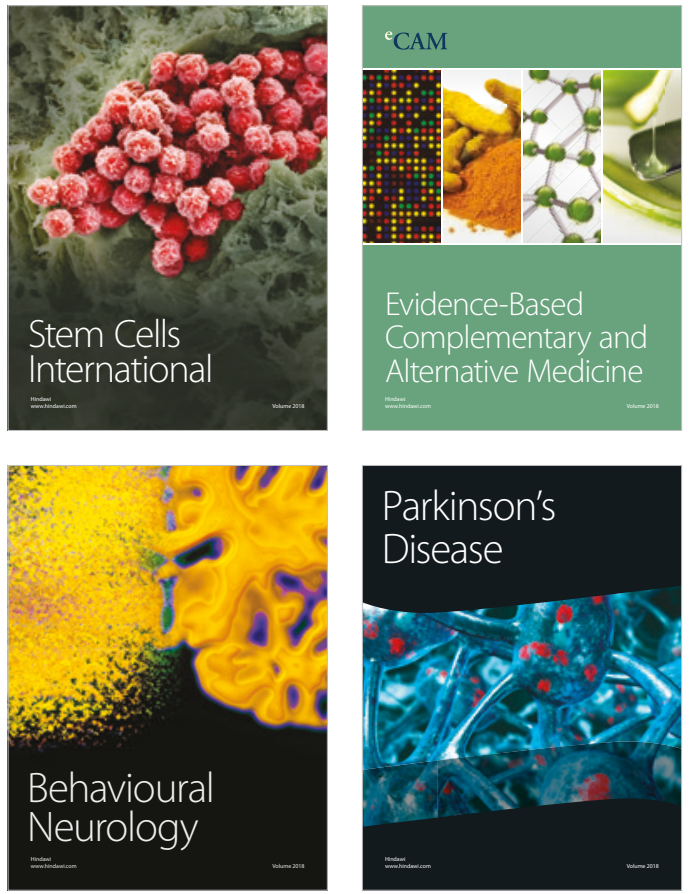

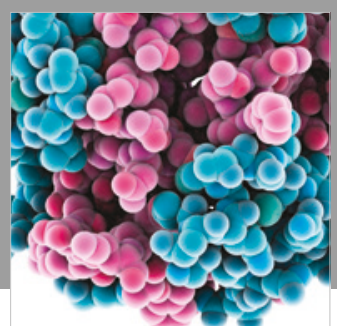

ournal of

Diabetes Research

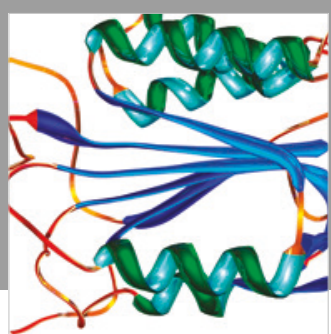

Disease Markers
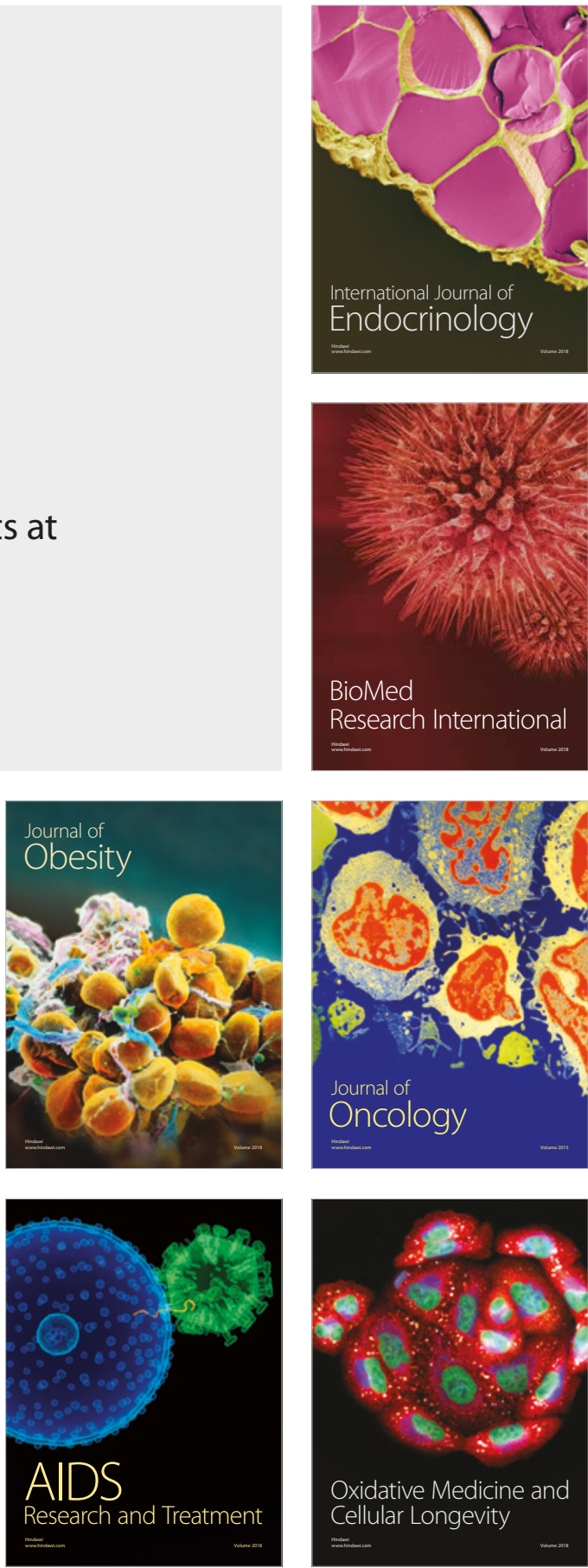